\title{
Assessment of Self Care Behaviors of Patients with Congestive Heart Failure: (Suggested Nursing Guidelines)
}

\author{
Esraa Nabil Mohammed, Ghona Abd El-naser Ali, Attyiat Hassan Hussein \& Ahmed Aly Obiedallah \\ Demonstrator of Medical, Surgical Nursing, Faculty of Nursing, Sohag, University Egypt. \\ Assistant professor of Medical, Surgical Nursing, Faculty of Nursing, Sohag, University Egypt. \\ Lecturer of Adult Nursing, Medical-Surgical Nursing, Faculty of Nursing, Assiut, University Egypt. \\ Lecturer of Internal Medicine, Faculty of Medicine, Assiut University Egypt.
}

\begin{abstract}
Aim: to assess self care behavior of patients with heart failure, design suggested nursing guidelines for patients with heart failure. Subjects and methods; The study was conducted in the internal medicine department and cardiac clinic at Assiut University Hospital. A convenience sample of 60 adult patients with congestive heart failure grade I, II, III from both males and females aged between (18-65) years old were included in this study. Tools; Tool (1) patient assessment sheet and Tool (2) Heart Failure Self-Care behavior Scale. Results; The findings revealed that the majority of patients aged between (41-60) yrs old, regarding to patient's knowledge, (60\%) of patients had unsatisfactory level of knowledge, there was a statistical significant relation between self care behavior and knowledge. Conclusion; Based on findings of the present study, it can be concluded that, patients were not adherent to self care behaviors; Socio demographic characteristic had clear effect on the knowledge of the patients. Also, the study concluded high percentage from patients had poor knowledge which affected on patients self care behavior; results of this study could be useful for the development of nursing interventions that can promote/improve self-care in this population. Recommendations: Health education including the suggested nursing guidelines for patients with congestive heart failure is mandatory to improve self care behavior.
\end{abstract}

\section{Key Words: Congestive Heart Failure, Self Care Behavior, Nursing Guidelines.}

\section{Introduction}

Congestive heart failure $(\mathrm{CHF})$ is considered an epidemic health problem, its incidence and prevalence have increased globally, and heart disease is one of the most leading causes of death. It is a condition in which the heart has lost the ability to pump enough blood to the body's tissues. With too little blood being delivered, the organs and other tissues do not receive enough oxygen and nutrients to function properly (WHO, 2008).

Chronic diseases are the main causes of mortality worldwide, with heart failure standing out as one of the leading causes of hospitalization and high rates of morbidity and mortality in many countries. Congestive heart failure is currently one of the major public health problems, and its complex and progressive nature often results in adverse events, such as high rate of re-hospitalization and mortality, which could be reduced if there were appropriate self-care (Riegel et al., 2011).

Self-care in chronic diseases is related to the maintenance of the appropriate level of physical and psychological well-being; decrease in morbidity and mortality and in the use and cost of healthcare, increase in patient's satisfaction, improvement of control sense and life quality, reasons by which self care is a central concern in the care for people with chronic diseases (Schnell et al., 2009).
The self-care concept has evolved over the years. It is associated with autonomy, independence and individual responsibility for healthy behaviors, as well as for the development of activities required to manage and monitor health conditions (Riegel et al., 2009).

The illness experience requires that people integrate practices and recommendations to self-care, in order to maintain the greatest well-being possible. The selfcare promotion is essential in chronic disease by involving activities and skills that should be learned and used by the individuals to improve their quality of life (Wilkinson\& Whitehead, 2009).

In Congestive heart failure (CHF), self-care refers to the behaviors developed by people to maintain their health (self care maintenance) and decisions they make about worsening of symptoms when they occur (self-care management). The self-care maintenance involves adherence to pharmacological recommendations, consumption of a low-salt diet, cessation of tobacco use, limited alcohol consumption, daily monitoring of body weight, signs or symptoms, and congestive heart failure decompensation. From this perspective, self-care is a decision-making process that patients use in choosing behaviors that maintain physiological stability and 
response to the symptoms when they occur (Riegel et al., 2009).

Recent studies with samples of patients with congestive heart failure indicate that self-care is inappropriate (Tung et al., 2012) and individuals who participated in educational self-management programs showed a better self-care behavior (Agvall et al., 2013).

Self-care behavior is little studied and the variables that influence self-care are still little explored, which motivated this study. Knowing the self-care behavior in patients with $\mathrm{CHF}$ contributes to the understanding of this phenomenon and so that nurses recognize behaviors that need to be modified or added for a better disease control and consequently, a better quality of life for patients with congestive heart failure (Riegel et al., 2009).

Nurses play a fundamental role in the educational process and continuity of patient care. The objectives of these processes are to teach, reinforce, improve and constantly evaluate patients' self-care abilities, which include weight monitoring, sodium and fluid restrictions, physical activities, regular medication use, monitoring signs and symptoms of disease worsening and early search for medical care. Therefore, education to understand $\mathrm{CHF}$, development and designing of nursing guidelines are considered key points to improve adherence, avoid decompensation crises and, consequently, to maintain patients clinically stable (Carlson et al., 2009).

Significance of the study

Egyptians are most vulnerable to heart diseases at an early age. The possible causes are dietary changes, sedentary lifestyles, smoking and stress. In Egypt around 1, 5 million individuals have CHF and yearly incidence around 111,937 new cases diagnosed with $\mathrm{CHF}$, additionally WHO reported that $23 \%$ of recorded deaths were confirmed to heart failure in Egypt(Rönning, etal., 2012). And there is 250 cases diagnosed with congestive heart failure in Assuit University Hospital in 2014 (Assuit university hospital records, 2014).

Non-adherence to self care guidelines accounted for $50 \%$ of hospital readmissions in heart failure. We observed that patients with heart failure are facing many problems and expressing different needs related to their condition. Self care is the key to improve health for patients with heart failure; hence this work has been carried out to assess self care behavior of patients with congestive heart failure (Riegel, et al., 2000).

\section{Aim of the study}

The aims of this study were

- Assess self care behavior of patients with congestive heart failure.

- Design suggested nursing guidelines for improving self care behaviour of patients with congestive heart failure.

\section{Research questions}

This study is directed to answer the following question:

What is the patient's knowledge about self care behaviour of congestive heart failure?

Do patients adhere to self care behavior?

Operational definitions:

Self care behavior

Is the ability of individuals to promote health, prevent disease, maintain health and to cope with illness and disability with or without the support of a health care provider (Schnell et al., 2009).

Nursing guidelines

Statements that help practitioners and patients to make decisions about care to maintain patients clinically stable (Carlson et al., 2009).

Subjects and methods

Research design: A descriptive research design was utilized to fulfil the aim of this study.

Inclusion Criteria: Patients aged between (18-65) years old with congestive heart failure grade I, II, III from both male and female.

\section{I-Technical design}

Setting: The study was conducted in the internal medicine department and cardiac clinic at Assiut University Hospital.

Subjects: A convenience sample of 60 adult patients with congestive heart failure.

Sample size using power analysis

Flow of patients with Congestive heart failure during the previous year (2014) in Assiut university hospital about 250 cases; Sample size was estimated with statistical program (Mini tab 17) and determined according to this equation:-

$$
\mathrm{Ss}=\frac{\mathrm{Z}^{2} \mathrm{P}(1-\mathrm{p})}{\mathrm{C} 2}
$$

Where $\mathrm{Z}=1.96 \quad \mathrm{C}=0.11 \quad \mathrm{p}=0.5$

New ss $=\underline{\mathrm{sS}}$

$$
\left(1+\frac{\mathrm{ss}-1}{\text { Pop })}\right.
$$

(Pop) is the population $=250$

New ss $=57$

Minimal required sample $=57$ 
Tools

Tool 1: Patient assessment sheet; it includes three parts:

Part I: Socio demographic data:

This part collected the necessary data about study subject. It was included of questions covering the following; age, sex, level of education, marital status, occupation.

\section{Part II: Patient medical data}

It was included the following: history of current disease, past medical diseases, family history, smoking status and medication.

Part III: Assessment of patient knowledge: This was developed by the researcher based on the review of literature; this part was used to assess:

1- Patient's knowledge about heart failure such as definition, types, signs and symptoms, causes and complications.

2-Patient's knowledge about types of medication such as action, side effects precautions and complications.

3- Barriers for self care such as (Physical limitation, feeling lack of energy, Lack of knowledge....etc)

\section{Scoring system}

Total score is 10 , each complete answer was get score of (2) and incomplete answer was get score of (1) but unknown answer was get score of (0).Patients who scored more than $(50 \%)$ were considered as having satisfactory level of knowledge and those who scored less than $(50 \%)$ were considered as having unsatisfactory level of knowledge.

Tool 2: Heart Failure Self-Care behavior Scale (HFSCBS): this tool was developed by (Artinian, 2002) comprises 28 items to assess the frequency of self-care behaviors. It has four levels for the questions.

\section{It includes three parts}

Part I: -Request for help during the disease; it comprised 7 items(feel out of breath, swelling of feet, ankles, legs, or stomach, feel tired, feel nausea, loss of appetite and breathlessness)

Part II: -Adaptation to the disease; it comprised 7items, these items measure patient adaptation to the disease and adherence to medication it included( adapting to the condition of having HF, living happily having HF, talking to the doctor and my family about changes and plans for the future, taking the medication prescribed by the doctor for HF', ' buying or request the medication on time, having a system to remember when patient should take the medication and trying to share with someone when patient feel anxious).

Part III: Adherence to the non-pharmacological treatment; it comprised 14 items (measuring the amount of urine on a daily basis, reducing the intake of foods rich in salt, engaging in physical activity three to four times per week, distributing the day's activities to keep from getting too tired, rest in bed three times per day after activities requiring effort and keep away from people with colds,.......etc).

Scoring system:

Had four levels of the questions: $0=$ never, $1=$ a few times, 2 = almost always, and $3=$ always. To score the scale, the score for each item is added; the higher the score, the higher the level of self-care, with 84 being the maximum score. Those who obtained less than $(50 \%)$ were considered having unsatisfactory level of self care behaviour. More than $(50 \%)$ were considered having satisfactory level of self care behaviour.

\section{II- Operational design \\ The study was carried out on two phases Preparatory phase}

Patient's agreement for voluntary participation was obtained, the purpose and nature of the study was explained to the patient, this phase started by a review of current and past, local and international related literature in the various aspects of the problems using books, articles, periodicals, and magazines was done, and ended by content validity and pilot study.

\section{Content validity and reliability}

It was established by panel of 5 experts from the staff of medicine and nursing field who reviewed the instruments and nursing guidelines for clarity, relevance, comprehensiveness and applicability. The content validity of this tool was checked by expert professors in medical surgical nursing and correction was carried out accordingly. Then the final form of tool 2 Heart Failure Self-Care behavior Scale (HFSCBS) was designed and tested for reliability by using internal consistency for the tools measured using Cronbach test, the tool proved to be reliable (Cronbach's Alpha $=0.96$ ).

\section{Pilot study}

Pilot study was conducted on $10 \%$ of sample (6 patients) in a selected setting to evaluate the applicability \& clarity of the tools. According to this pilot study, the required modifications were made. Those patients who were involved in the pilot study were included in the study.

\section{Ethical considerations}

-Research proposal was approved from ethical committee in the faculty of nursing.

-Written consent was obtained from patients or guidance that was willing to participate in the study after explaining the nature and purpose of the study.

-There was no risk for study subject during application of the research

-The study followed common ethical principles in clinical research.

-Confidentiality of patient's data was assured. 
-Patients had the right to refuse to participate and/or withdraw from the study without any rational at any time.

-Study subject privacy was considered during collection of data.

\section{Implementation phase}

Data were collected at internal medicine department and cardiac clinics at Assiut University Hospital during the period from $3 / 11 / 2015$ to $15 / 2 / 2016$. At initial interview the researcher introduced herself to initiate line of communication in order to facilitate the implementation of the tools. The patient was interviewed individually and assessed by using (tool I and tool II) the tools were all filled through interviewing. The purpose of the study was explained to the patients prior to answering the questions. The study was carried out during morning and afternoon shifts for all available patients.

\section{Statistical design}

The collected data were tabulated and statistically analyzed to Assess self care behavior of patients with heart failure under study as regards the various variables by computer program SPSS" ver. 16" Chicago. USA Data expressed as number and percentage, it is considered significant when $\mathrm{P} \leq 0.05$ significant and non- significant when $\mathrm{P}>0.05$.

\section{Results}

Table (1): Distribution of patients regarding to their socio-demographic characteristics.

\begin{tabular}{|c|c|c|}
\hline Characteristics & No. $(n=60)$ & $\%$ \\
\hline \multicolumn{3}{|l|}{ Age:(years) } \\
\hline 18 & 2 & 3.3 \\
\hline 40 & 57 & 95 \\
\hline $60-65$ & 1 & 1.7 \\
\hline \multicolumn{3}{|l|}{ Gender } \\
\hline Male & 42 & 70 \\
\hline female & 18 & 30 \\
\hline \multicolumn{3}{|l|}{ Marital status } \\
\hline Single & 3 & 5 \\
\hline Married & 45 & 75 \\
\hline Divorced & 3 & 5 \\
\hline Widow & 9 & 15 \\
\hline \multicolumn{3}{|l|}{ Level of Education } \\
\hline Illiterate & 50 & 83.3 \\
\hline Read and write & 5 & 8.3 \\
\hline Primary education. & 2 & 3.3 \\
\hline High education & 3 & 5 \\
\hline \multicolumn{3}{|l|}{ Occupation } \\
\hline Employee & 2 & 3.3 \\
\hline Farmer & 33 & 55 \\
\hline Technician & 7 & 11.7 \\
\hline Housewife & 18 & 30 \\
\hline No work & --- & --- \\
\hline
\end{tabular}


Table (2): Distribution of patients regarding to their medical data.

\begin{tabular}{|c|c|c|}
\hline Medical data & No. $(n=60)$ & $\%$ \\
\hline $\begin{array}{l}\text { Duration of disease } \\
\text { More than } 5 \text { yrs }\end{array}$ & 15 & 25 \\
\hline Less than 5 yrs & 15 & 25 \\
\hline Do not know & 30 & 50 \\
\hline $\begin{array}{l}\text { Chronic diseases } \\
\text {-Hypertension } \\
\text { Yes }\end{array}$ & 10 & 16.7 \\
\hline No & 50 & 83.3 \\
\hline $\begin{array}{l}\text {-Diabetes mellitus } \\
\text { Yes }\end{array}$ & 2 & 3.3 \\
\hline No & 58 & 96.7 \\
\hline $\begin{array}{l}\text { High cholesterol } \\
\text { Yes }\end{array}$ & -- & -- \\
\hline No & 40 & 66.7 \\
\hline Do not know & 20 & 33.3 \\
\hline $\begin{array}{l}\text { Family history } \\
\text { Yes }\end{array}$ & 3 & 5 \\
\hline No & 50 & 83.3 \\
\hline Do not know & 7 & 11.7 \\
\hline $\begin{array}{l}\text { Smoking } \\
\text { Yes }\end{array}$ & 42 & 70 \\
\hline No & 18 & 30 \\
\hline
\end{tabular}

Table (3): Distribution of the total score of the patient's knowledge about heart failure.

\begin{tabular}{|l|c|c|}
\hline knowledge & No. $(\mathbf{n}=\mathbf{6 0})$ & \% \\
\hline Satisfactory & 24 & 40 \\
\hline Unsatisfactory & 36 & 60 \\
\hline
\end{tabular}

Table (4): Relationship between patient's knowledge and socio-demographic characteristics.

\begin{tabular}{|c|c|c|c|c|c|}
\hline \multirow{2}{*}{ Characteristics } & \multicolumn{2}{|c|}{ Satisfactory } & \multicolumn{2}{|c|}{ Unsatisfactory } & \multirow{2}{*}{ P-value } \\
\hline & No. & $\%$ & No. & $\%$ & \\
\hline \multicolumn{5}{|l|}{ Age:(years) } & \multirow{4}{*}{$0.002 * *$} \\
\hline 18 & 2 & 100 & 0 & 0 & \\
\hline 40 & 21.4 & 37.5 & 35.6 & 62.5 & \\
\hline $60-65$ & 0.2 & 20 & 0.8 & 80 & \\
\hline \multicolumn{5}{|l|}{ Gender } & \multirow{3}{*}{0.114} \\
\hline Male & 18.2 & 43.3 & 23.8 & 56.7 & \\
\hline Female & 5.4 & 30 & 12.6 & 70 & \\
\hline \multicolumn{5}{|l|}{ Marital status } & \multirow{5}{*}{0.145} \\
\hline Single & 3 & 100 & 0 & 0 & \\
\hline Married & 15.8 & 35.1 & 29.2 & 64.9 & \\
\hline Divorced & 2 & 66.7 & 1 & 33.3 & \\
\hline Widow & 3.6 & 40 & 5.4 & 60 & \\
\hline \multicolumn{5}{|l|}{ Level of Education } & \multirow{5}{*}{$0.007 * *$} \\
\hline Illiterate & 16 & 32 & 34 & 68 & \\
\hline Read and write & 2.8 & 56 & 2.2 & 44 & \\
\hline Primary education. & 1.8 & 90 & 0.2 & 10 & \\
\hline High education & 3 & 100 & 0 & 0 & \\
\hline
\end{tabular}




\begin{tabular}{|l|c|c|c|c|c|}
\hline \multirow{2}{*}{ Characteristics } & \multicolumn{2}{|c|}{ Satisfactory } & \multicolumn{2}{c|}{ Unsatisfactory } & \multirow{2}{*}{ P-value } \\
\cline { 2 - 5 } & No. & \% & No. & \% & \\
\hline Occupation & 2 & 100 & 0 & 0 & \multirow{2}{*}{0.076} \\
\hline Employee & 11.4 & 34.5 & 21.6 & 65.5 & \\
\hline Farmer & 4.8 & 68.6 & 2.2 & 31.4 & \\
\hline Technician & 5.4 & 30 & 12.6 & 70 & \\
\hline Housewife & -- & -- & -- & -- & \\
\hline No work & \multicolumn{7}{|l|}{} & & \\
\hline
\end{tabular}

Table (5): Distribution of the total mean score of the patients' self care behavior.

\begin{tabular}{|l|l|c|c|c|c|c|c|c|c|}
\hline \multirow{2}{*}{\multicolumn{2}{|c|}{ Item }} & \multicolumn{2}{c|}{ Never 0 } & \multicolumn{2}{c|}{ Few times 1 } & \multicolumn{2}{c|}{ Almost always 2 } & \multicolumn{2}{c|}{ Always 3 } \\
\cline { 2 - 10 } & $\begin{array}{c}\text { mean } \pm \\
\text { SD }\end{array}$ & $\%$ & $\begin{array}{c}\text { mean } \pm \\
\text { SD }\end{array}$ & $\%$ & $\begin{array}{c}\text { mean } \pm \\
\text { SD }\end{array}$ & $\%$ & $\begin{array}{c}\text { mean } \pm \\
\text { SD }\end{array}$ & $\%$ \\
\hline $\mathbf{1}$ & Request for help & $7.86 \pm 16.1$ & 13.10 & $21.99 \pm 15$ & 36.65 & $19.29 \pm 12.4$ & 32.15 & $10.85 \pm 7.5$ & 18.08 \\
\hline $\mathbf{2}$ & $\begin{array}{l}\text { Adaptation to the } \\
\text { disease }\end{array}$ & $18.71 \pm 22.5$ & 31.18 & $8.57 \pm 16.1$ & 14.28 & $9.86 \pm 9.4$ & 16.43 & $22.86 \pm 20.8$ & 38.10 \\
\hline $\mathbf{3}$ & $\begin{array}{l}\text { Adherence to the } \\
\text { non-pharmacological } \\
\text { treatment }\end{array}$ & $44.00 \pm 17.5$ & 73.33 & $10.07 \pm 11.1$ & 16.78 & $2.71 \pm 5.4$ & 4.52 & $3.21 \pm 8.7$ & 5.35 \\
\hline
\end{tabular}

Table (6): Relationship between self care behavior and socio-demographic data.

\begin{tabular}{|c|c|c|c|c|c|c|c|c|c|c|c|c|c|}
\hline \multirow[t]{2}{*}{ Characteristics } & \multicolumn{4}{|c|}{ Request for help } & \multicolumn{4}{|c|}{ Adaptation to disease } & \multicolumn{4}{|c|}{$\begin{array}{l}\text { Adherence to non } \\
\text { pharmacological } \\
\text { treatment }\end{array}$} & \multirow[t]{2}{*}{$P$ value } \\
\hline & 0 & 1 & 2 & 3 & 0 & 1 & 2 & 3 & 0 & 1 & 2 & 3 & \\
\hline \multicolumn{13}{|l|}{ Age(years) } & \multirow{4}{*}{$0.032^{*}$} \\
\hline 18 & 0.00 & 0.00 & 0.00 & 5.00 & 0.00 & 0.00 & 0.00 & 5.00 & 0.00 & 0.00 & 0.00 & 5.00 & \\
\hline 40 & 11.43 & 36.65 & 32.17 & 13.08 & 29.50 & 14.28 & 16.43 & 33.10 & 71.67 & 16.78 & 4.52 & 0.35 & \\
\hline $60-65$ & 1.67 & 0.00 & 0.00 & 0.00 & 1.67 & 0.00 & 0.00 & 0.00 & 1.67 & 0.00 & 0.00 & 0.00 & \\
\hline \multicolumn{13}{|l|}{ Gender } & \multirow{3}{*}{0.0735} \\
\hline Male & 42 & 0.00 & 19.75 & 32.17 & 18.08 & 2.83 & 12.62 & 16.43 & 38.10 & 43.33 & 16.78 & 4.52 & \\
\hline Female & 18 & 13.10 & 16.90 & 0.00 & 0.00 & 28.33 & 1.67 & 0.00 & 0.00 & 30.00 & 0.00 & 0.00 & \\
\hline \multicolumn{13}{|l|}{ Marital status } & \multirow{5}{*}{0.19} \\
\hline Single & 0.00 & 0.00 & 0.00 & 5.00 & 0.00 & 0.00 & 0.00 & 5.00 & 0.00 & 0.00 & 0.00 & 5.00 & \\
\hline Married & 0.00 & 29.50 & 32.17 & 0.00 & 16.17 & 9.28 & 16.43 & 33.10 & 58.33 & 0.00 & 4.50 & 0.33 & \\
\hline divorced & 3.00 & 2.00 & 0.00 & 0.00 & 5.00 & 0.00 & 0.00 & 0.00 & 5.00 & 11.67 & 0.00 & 0.00 & \\
\hline widow & 10.00 & 5.00 & 0.00 & 0.00 & 10.00 & 5.00 & 0.00 & 0.00 & 10.00 & 5.00 & 0.00 & 0.00 & \\
\hline \multicolumn{13}{|l|}{ Education } & \multirow{5}{*}{$0.020^{*}$} \\
\hline illiterate & 13.10 & 36.65 & 32.17 & 1.42 & 31.17 & 14.28 & 16.43 & 21.43 & 73.33 & 10.00 & 0.00 & 0.00 & \\
\hline Read and write & 0.00 & 0.00 & 0.00 & 8.33 & 0.00 & 0.00 & 0.00 & 8.33 & 0.00 & 6.67 & 1.67 & 0.00 & \\
\hline $\begin{array}{l}\text { Primary } \\
\text { education }\end{array}$ & 0.00 & 0.00 & 0.00 & 3.33 & 0.00 & 0.00 & 0.00 & 3.33 & 0.00 & 0.00 & 2.83 & 0.50 & \\
\hline High education & 0.00 & 0.00 & 0.00 & 5.00 & 0.00 & 0.00 & 0.00 & 5.00 & 0.00 & 0.00 & 0.00 & 5.00 & \\
\hline \multicolumn{13}{|l|}{ Occupation } & \multirow{5}{*}{0.0885} \\
\hline Farmer & 0.00 & 36.65 & 15.00 & 3.08 & 10.33 & 11.67 & 16.43 & 16.67 & 43.33 & 11.67 & 0.00 & 0.00 & \\
\hline Technician & 0.00 & 0.00 & 0.00 & 11.67 & 0.00 & 0.00 & 0.00 & 11.67 & 0.00 & 5.00 & 4.50 & 2.00 & \\
\hline housewife & 13.10 & 0.00 & 17.17 & 0.00 & 20.83 & 2.83 & 0.00 & 6.43 & 30.00 & 0.00 & 0.00 & 0.00 & \\
\hline employee & 0.00 & 0.00 & 0.00 & 3.33 & 0.00 & 0.00 & 0.00 & 3.33 & 0.00 & 0.00 & 0.00 & 3.33 & \\
\hline
\end{tabular}


Table (7): Relationship between self care behavior and knowledge.

\begin{tabular}{|c|c|c|c|c|c|c|}
\hline \multirow{2}{*}{ Items } & \multirow{2}{*}{ score } & \multicolumn{2}{|c|}{ Satisfactory } & \multicolumn{2}{|c|}{ Unsatisfactory } & \multirow{2}{*}{$P$-value } \\
\hline & & No. & $\%$ & No. & $\%$ & \\
\hline \multirow{4}{*}{ Request for help } & $\mathbf{0}$ & 00 & 0.00 & 7.86 & 13.10 & \multirow{12}{*}{$0.0122 *$} \\
\hline & 1 & 00 & 0.00 & 21.99 & 36.65 & \\
\hline & 2 & 12.8 & 21.33 & 6.5 & 10.83 & \\
\hline & 3 & 10.85 & 18.08 & 00 & 0.00 & \\
\hline \multirow{4}{*}{ Adaptation to disease } & $\mathbf{0}$ & 00 & 0.00 & 18.7 & 31.17 & \\
\hline & 1 & 00 & 0.00 & 8.57 & 14.28 & \\
\hline & 2 & 1 & 1.67 & 8.8 & 14.67 & \\
\hline & 3 & 22.86 & 38.10 & 00 & 0.00 & \\
\hline \multirow{4}{*}{$\begin{array}{l}\text { Adherence to } \\
\text { pharmacological } \\
\text { treatment }\end{array}$} & $\mathbf{0}$ & 7.6 & 12.67 & 36.4 & 60.67 & \\
\hline & 1 & 10.07 & 16.78 & 00 & 0.00 & \\
\hline & 2 & 2.7 & 4.50 & 00 & 0.00 & \\
\hline & 3 & 3.2 & 5.33 & 00 & 0.00 & \\
\hline
\end{tabular}

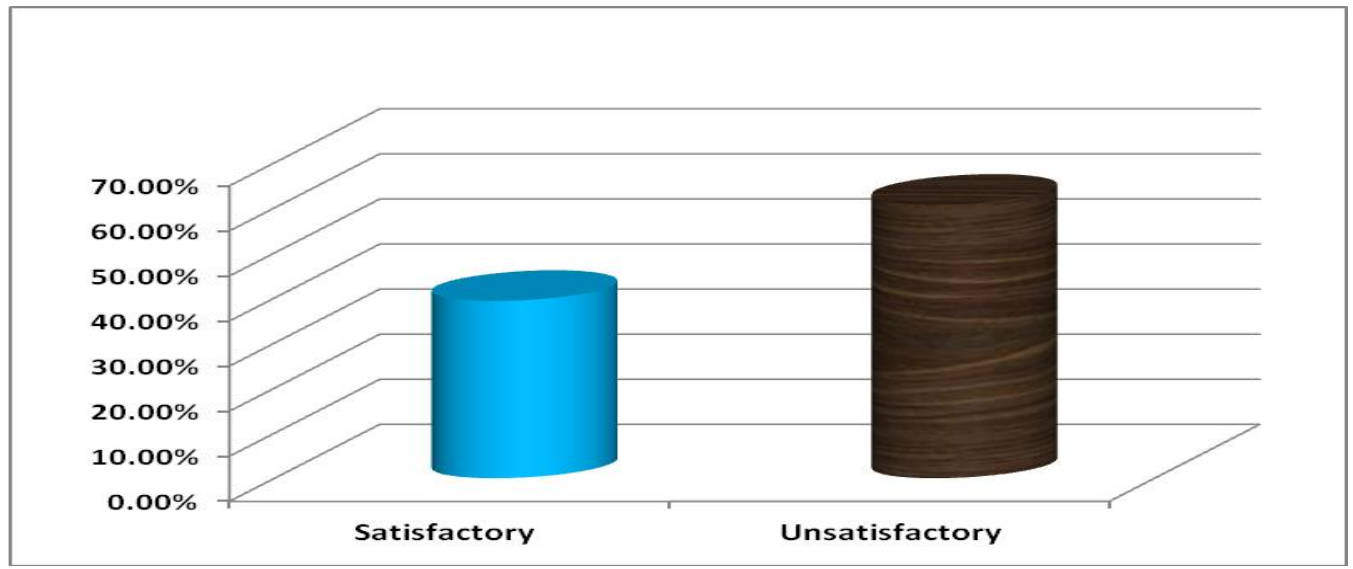

Fig (1): Distribution of the total score of the patient's knowledge about heart failure.

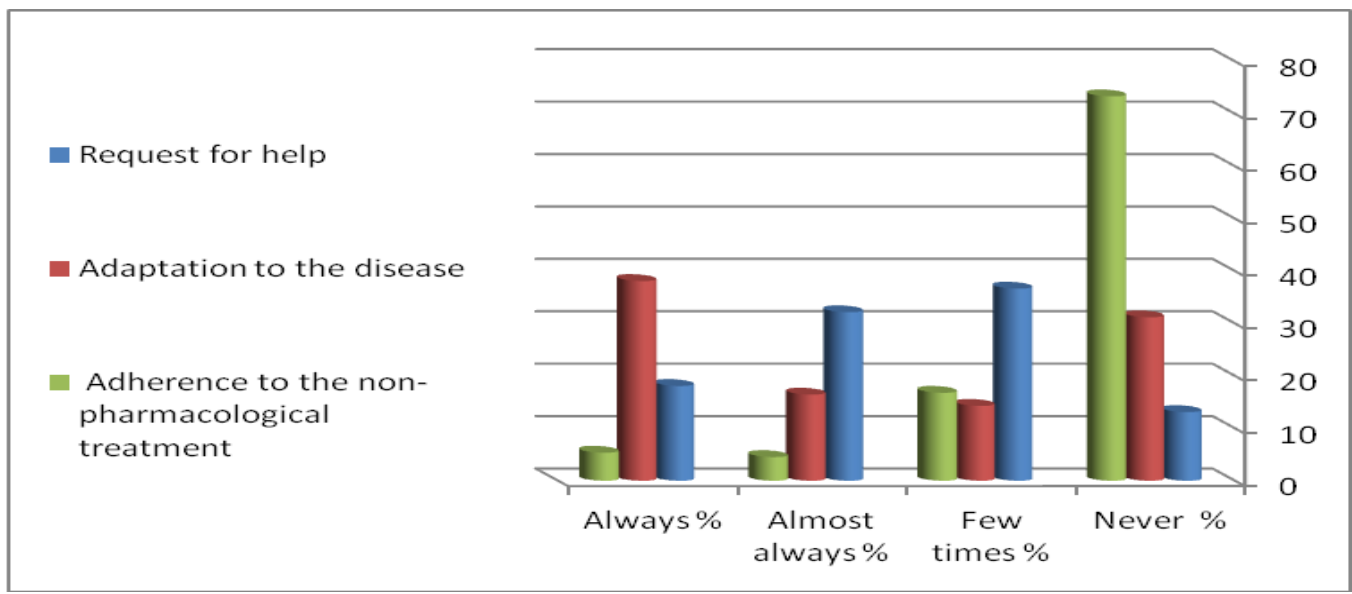

Fig (2) Distribution of the total mean score of the patients' self care behavior. 
Table (1): This table shows the distribution of patients regarding to their socio-demographic characteristics at Assuit University Hospital. It was noticed that the majority of patients were aged between (41-60) years old, males, married and $(83.3 \%)$ of them were illiterate. According to occupation, it was observed that $(55 \%)$ of patients were farmers.

Table (2): This table shows the distribution of patients regarding to their medical data, it shows that $(50 \%)$ of patients did not know the duration of disease and $(70 \%)$ of patients were smokers.

Table (3): This table shows the distribution of the total score of the patient's knowledge about heart failure, it shows that $(40 \%)$ of patients had satisfactory level of knowledge about heart failure, while $(60 \%)$ of patients had unsatisfactory level of knowledge.

Table (4): This table shows that statistical significant relation was noticed regarding to patients' knowledge, age and level of education at $\mathrm{P}$ - value (0.002\&0.007) respectively.

Table (5): This table shows the distribution of the total score of the patients' self care behavior, it shows that $(18.08 \%)$ of patients reported that they always request for help, while $(13.10 \%)$ of them were never request for help. Nearly $(38.10 \%)$ of patients reported that they always adapt to the disease, while $(31.18 \%)$ of them were never adapt to the disease. The majority of patients $(73.33 \%)$ reported that they never adherent to the non-pharmacological treatment, while $(5.35 \%)$ only of them reported that they always adherent to the non-pharmacological treatment.

Table (6): This table shows that, there was statistical significant relation between patients' self care behavior, age\& level of education at $\mathrm{P}$ - value (0.0322\&0.0202) respectively.

Table (7): this table shows that there was a statistical significant relation between self care behavior and knowledge at $\mathrm{P}<0.05$.

Fig (1): This figure illustrates that, $(40 \%)$ of patients had satisfactory level of knowledge about heart failure, while $(60 \%)$ of patients had unsatisfactory level of knowledge.

Fig (2): This figure illustrates that, (18.08\%) of patients reported that they always request for help, while $(13.10 \%)$ of them were never request for help. Nearly $(38.10 \%)$ of patients reported that they always adapt to the disease, while $(31.18 \%)$ of them were never adapt to the disease. The majority of patients (73.33\%) reported that they never adherent to the non-pharmacological treatment, while $(5.35 \%)$ only of them reported that they always adherent to the non-pharmacological treatment

\section{Discussion}

Self-care behavior, a key concept in health promotion, refers to decisions and actions that an individual can take to cope with a health problem or to improve his or her health. Self-care is generally viewed as a complement to professional health care for persons with chronic health conditions (Siabani et al., 2013).

In the present study, findings regarding to patients' characteristics revealed that, congestive heart failure is common among patients aged between (41-60) years old and more common in males this result is supported by Jacobsen et al., (2011) who found that more than half of heart failure patients admitted to hospital aged between (41-60) years old, and this syndrome affects men more than women.

Concerning their educational level, the present study results revealed that more than half of heart failure patients were illiterate, while $(8.3 \%)$ of them can read and write. this results are similar to Baker et al., (2011) who reported that the majority of the studied sample were illiterate.

Regarding to marital status, the current study results revealed that more than fifty percent of the patients were married, while five percent only of them were single, this result is supported by Luttik et al., (2006).This result disagrees with the American College of Cardiology, (2014) which reported that people who are married have lower rates of several cardiovascular diseases compared with those who are single, divorced or widowed.

As regards occupation of the studied patients, the present study revealed that more than fifty percent of the patients were farmers, while less than five percent of patients were employee, these findings may be attributed to the nature of the education level of studied patients. This result is supported by Jaglal, and Goel, (2011). This result disagrees with Buring et al., (2010) who reported that a higher cardiovascular disease (CVD) risk in those in the high social class.

The present study results showed that more than fifty percent of patients reported that they had not family history of the disease, concerning patients habits as smoking; this study revealed that, more than half of male patients were smokers, this result is supported by Khaw et al., (2010) who reported that family history of heart failure was an independent predictor of cardiovascular disease and cigarette smoking was a stronger predictor of cardiovascular disease.

Similar to the present study Lainscak \& Keber, (2010) stated that more than fifty percent of patients had unsatisfactory level of knowledge about signs and symptoms, causes, medication of heart failure, facilities and barriers of self care. 
As regard the relationship between knowledge and socio-demographic characteristics of patients; this study showed that, statistical significant relation between patient's knowledge and age, this result is supported by Joyce et al., (2011) who reported that young patients had general informations about the disease more than older ones.

Macabasco et al., (2011) reported that positive association was found between health literacy and patient knowledge in heart failure, and this relationship also, has been observed for other diseases and chronic conditions This result consistent with Chen et al., (2014) who added that literacy was the primary influence on knowledge about heart failure and there was significant relation between patient's knowledge and education.

The present study results revealed that nonsignificant relation was founded between patient's knowledge and gender, this result is supported by chung et al., (2011), who reported that patient's sex is not associated with his/her knowledge. However, this finding disagrees with Nauman et al.,(2009) who reported that women were more knowledgeable about heart failure management than men.

Regarding the self-care dimensions posed by the HFSCBS, in the dimension of request for help, this study show that less than twenty percent of patients reported that they always request for help, while thirteen percent of them were never request for help, this result is supported by Penny, (2010) who reported in his study that many heart failure patients delay in calling for help.

Another aspect related to requesting help is associated to recognizing the symptoms and the need for consultation before the symptoms worsen. These topics are aspects that are frequently dealt with in educational programs and those in which the patients and their caretakers pay greater attention to chest pain and to the sense of breathlessness; perceived by patients as evident risk of dying and for which they frequently consult (Leslie et al., 2009).

Regarding the dimension of adaptation to the disease, this study show that less than fifty percent of patients reported that they always adapt to the disease, and less than fifty percent of them were never adapt to the disease, this result is supported by Welstand et al., (2009) who reported that patients with $\mathrm{HF}$ find it easier to follow the treatment and live with the symptoms if they have adapted to the disease.

In the dimension of adherence to the nonpharmacological treatment, the majority of patients reported that they never adherent to the nonpharmacological treatment, this result is supported by Gonzalez et al., (2010) who reported that one of the hardest behaviors to improve was the decrease of salt intake, which has been related to the patient's inadequate knowledge on managing this behavior.

As regard the relationship between self care behavior and socio-demographic characteristics of patients has been found a statistical significant relation between patients' self care behavior and age, this result is supported by Cocchieri et al., (2014) who reported that young patients took care of themselves better than old ones, decreased self care ability may be due to increasing visual, hearing impairment with age and loss of perception, these factors may cause heart failure self care more difficult.

Regarding to the relationship between patients' self care behavior and educational level, this study show that there was a statistical significant relation, this result is supported by Abootalebi et al., (2012). This result disagrees with Dunlay et al., (2011) who reported that no significant relation between patients' self care behavior and level of education.

Similar to the present study Huyen et al., (2011) stated that no-significant relation was founded between patient's self care behavior and gender. This result is in contrast with Shojaei et al., (2009) who reported in their study that women demonstrated better adherence to self care than men.

As regard the relationship between patient's self care behavior and occupation. It has been found nonsignificant relation between patient's self care behavior and occupation. This result is supported by Jaglal, \& Goel, (2011). While, this result is in disagreement with Buring et al., (2010) who reported that patients in the high social class took care of themselves better than those in low social class.

Concerning the relationship between patient's self care behavior and marital status. It has been found non-significant relation between patient's self care behavior and marital status. This result disagrees with Sandra, (2009) who reported that heart failure patients without spouse and those who live alone and are highly vulnerable for poor self-care.

In the present study, relationship between self care behavior and knowledge has been found significant relationship; this result is supported by Jaarsma et al., (2006) who reported that lack of patient's knowledge affect self care behavior.

Finally, based on this study results; literacy was the primary influence on knowledge about heart failure. There was a statistical significant relation between patients' self care behavior and age, and level of education, while there was no significant relation between self care behavior and marital status, occupation, and gender and there was a statistical significant relation between self care behavior and knowledge. 


\section{Conclusion}

Based on findings of the present study, it can be concluded that, self-care has been shown as inappropriate; results of this study could be useful for the development of nursing interventions that can promote/improve self-care in this population, especially by means of the use of self-care model in heart failure (HF) to develop interventions. Educational actions, nursing consultations, can and should be used to empower patients to symptoms recognition and management.

Socio demographic characteristic had clearly effect on the knowledge of the patients; also the study concluded high percentage from patients had poor knowledge which affect patients self care behavior. The majority of patients in this study reported to be non adherent to self care which increases the risk for adverse outcomes; further efforts are needed to improve self care. This can help healthcare providers to focus on these patients and to implement education and counselling targeted at improving adherence and, therefore, reducing risk for adverse outcomes.

\section{Recommendations}

Based on the finding of this study, following recommendations were made:

\section{For Nurses}

- Increase awareness of patients who had heart failure to improve self care behavior.

- Constructing an educational program should be designed by nurses to increase people knowledge about causes, signs and symptom and treatment of heart failure.

- Interventions and nursing guidelines that focus on specific self-care behaviors may be more effective than general educational programs.

\section{In services}

Changes in some health care systems and national policies are needed to support patients with -heart failure to increase their self-care behavior.

For research (future study)

Designing and application nursing care standard for patient's self care behavior.

\section{References}

1. Abootalebi G., Nejad, M., Namadi M., \& Kaji (2012): Study of the self care in patients with heart failure-Iran J.crit.care Nursing, Vol 4,P 203-208.

2. Agvall B., Alehagen U., \& Dahlström (2013): The benefits of using a heart failure management programme in Swedish primary healthcare. Eur J Heart Fail. Vol15, No2, PP. 228-36.
3. American college of cardiology (2014): Available at http://www.acc.org/about-acc/pressreleases/2014/03/28/09/55/alviar-marital-status., Mar 28, 2014

4. Artinian N., Morris M., \& Sloan M., (2002): Self-care behaviors among patients with heart failure. Issues in Cardiovascular Nursing. Heart Lung. vol 31 ,No.3,PP.161-72.

5. Assuit university hospital records, (2014).

6. Baker D., Asch S., Keesey J., Brown J., Chan K., Joyce G., et al., (2011): Differences in education, knowledge, self-management activities, and health outcomes for patients with heart failure cared for under the chronic disease model: the improving chronic illness care evaluation. J Card Fail.Vol 11, No 6, PP. 405-13.

7. Buring J., Evans D., Fiore M., et al., (2010): Occupation and risk of coronary heart disease. JAMA Vol258, P 791-2.

8. Carlson B, Riegel $B$ and Moser DK (2009): Self-care abilities of patients with heart failure. Heart \& Lung Vol30, No. (5),PP.351-359.

9. Chen, Aleda M., Yehle, Karen, Albert, Nancy M., Ferraro, Kenneth F., Mason, Holly L., Murawski, Matthew M., \& Kimberly S., (2014): "Relationships between Health Literacy and Heart Failure Knowledge, Self-Efficacy, and Self-Care Adherence.School of Nursing Faculty Publications.

Paper 15.http://dx.doi.org/10.1016/j.sapharm.2014.07.0 01

10. Chung M., Lenni T., \& Moser D., (2011) : The impact of gender, marital staus on adherence to non pharmacological treatment, Vol 105, No 2, PP. 325-28.

11. Cocchieri A., B.Rigeal, F., Agostino, G., Rocco, R., fida \& E.Vellone (2014): Describing self care in adults with heart failure and identifying determinants of poor self care,Eur.J.cardiovasc.Nursing.Vol 10,PP.145-49

12. Dunlay S., WestonS A., Jacobsen S., \& Roger V., (2011): Risk factors for heart failure: a population-based case-control study. Am J Med; Vol122, PP. 1023-28.

13. González B., Lupón J., Herreros J., Urrutia A., Altimir S., Coll R., et al., (2010): Patient's education by nurse: what we really do achieve? Eur J Cardiovasc Nurs, Vol4, No.2, PP.107-11.

14. Huyen, N., Jullamate W., \& Kangchai (2011): Factors related to Self care behavior among people with heart failure proceeding of the $1^{\text {st }}$ international conference on interdisciplinary research and development, May 31June2011,PP.701-05

15. Jaarsma T., Moser D., Veeger N., van Gilst W., \& Veldhuisen D., (2006): Compliance in 
heartfailure patients: the importance of knowledge and beliefs. Eur Heart J Vol27, PP. 434-40.

16. Jacobsen S., Burnett J., Mahoney D., Bailey K., \& Rodeheffer R., (2011): The prevalence of heart failure in USA, Vol 289,No2,PP.194-02

17. Jaglal S., \& Goel V., (2011): Social inequity in risk of coronary artery disease in Ontario. Can Cardiol.Vol10, PP. 439-43.

18. Joyce G., Baker D., Asch S., Keesey J., Brown J., Chan K., et al., (2011): Differences in education, knowledge, self-management activities, and health outcomes for patients with heart failure cared for under the chronic disease model: the improving chronic illness care evaluation. J Card Fail.Vol11, No.6, PP. 405-13.

19. Khaw Kay-Tee, M., \& Elizabeth BarrettConnor (2010):M.D.Vol 74, No. 2, PP. 239-44.

20. Lainscak M., \& Keber I., (2010): Validation of self assessment. Patient knowledge questionnaire for heart failure patients. Eur $\mathrm{J}$ Cardiovasc Nurs.Vol(4)PP.155

21. Leslie W., Urie A., Hooper J., \& Morrison C., (2009): Delay in calling for help during myocardial infarction: reasons for the delay and subsequent pattern of accessing care. Heart failure.Vol 84, No.2, PP. 137-41.

22. Luttik M., Jaarsma T., Veeger N., \& Veldhuisen D., (2006): Marital status, quality of life, and clinical outcome in patients with heart failure. Heart Lung. Vol 35No1, PP. 3-8.

23. Macabasco-O'Connell A., DeWalt D., Broucksou K., et al., (2011): :Relationship between literacy, knowledge, self-care behaviors, and heart failure-related quality of life among patients with heart failure. J Gen Intern Med.Vol26, PP. 979-86.

24. Nauman D., Burgess D., Wise K., Crispell K., \& Hershberger R., (2009): Factors influencing knowledge of and adherence to self-care among patients with heart failure.Vol159, No.14, PP. 1613-9.

25. Penny W., (2010): Patient delay in calling for help: the weakest link in the chain of survival? Heart failure. Vol 85, No.2, PP. 121.

26. Riegel B., Carlson B., \& Glaser D., (2000): Development and testing of a clinical tool measuring self-management of heart failure. Heart Lung, Vol 29, PP. $4-12$.

27. Riegel B., Driscoll A., Suwanno J., Moser D., Lennie T., \& Chung M., (2011): Heart Failure Self-care in Developed and Developing Countries. J Card Failuire.Vol15,No6,PP. 50816

28. Riegel B., Lee C., Dickson V., \& Carlson B., (2009): An update on the self-care of heart failure index. J Cardiovasc Nurs. Vol24, No 6, PP. 485-97.

29. Rönning H., Arestedt K., \& Nielsen N., (2012): Development and psychometric evaluation of the knowledge scale for adults with cardiac diseases, Clinical epidemiology of heart failure. Heart $\mathbf{J}$ Cardiovascular Nurse, Vol 12, PP 78-86.

30. Sandra B., \& Dunbar (2009): J Cardiovasc Nurs, Relationship between self care behaviour and sociodemographic data of patients with heart failure, Vol23, No.3, PP. 258-65.

31. Schnell, Hoehn K., Naimark B., \& Tate R., (2009): Determinants of self-care behaviors in community-dwelling patients with heart failure. J Cardiovasc Nurs. Vol24, No1, PP.40-47.

32. Shojaei F., Asemi S., Njafiarandi A., \& HoseiniF (2009): Self -care behavior of patients with heart failure.Quarterly journal of paiesh. Vol8, No.(4) ,PP. 361-69

33. Siabani S., Leeder, \& P., Davidson (2013): Cardiovascular disease: Australian facts, cardiovascular disease series, Vol 35. AIHW, Canberra.

34. Tung H, Chen S, Yin W, Cheng C, Wang T., \& Wu S., (2012): Self care behavior in patients with heart failure in Taiwan. Eur $\mathrm{J}$ Cardiovasc Nurs.vol11,No 2,PP. 175-82

35. Welstand J., Carson A., \& Rutherford P., (2009): Living with heart failure: an integrative review. Int Nurs Stud, Vol 46, No.10, PP. 137485.

36. World Health Organization (WHO) (2008):Definition of heart failure Available at http://www.who.int/cardiovascular_diseases/en/

37. Wilkinson A., \& Whitehead L., (2009): Evolution of the concept of self-care and implications for nurses a literature review. Int $\mathbf{J}$ Nurs Stud.Vol46, N8, PP. 1143-47. 